\title{
Estimation of plasma fibrinogen levels based on hemoglobin, base excess and Injury Severity Score upon emergency room admission
}

\author{
Christoph J Schlimp ${ }^{1}$, Wolfgang Voelckel ${ }^{2}$, Kenji Inaba ${ }^{3}$, Marc Maegele ${ }^{4}$, Martin Ponschab ${ }^{5}$ and Herbert Schöchl $1^{1,2^{*}}$
}

\begin{abstract}
Introduction: Fibrinogen plays a key role in hemostasis and is the first coagulation factor to reach critical levels in massively bleeding trauma patients. Consequently, rapid estimation of plasma fibrinogen (FIB) is essential upon emergency room (ER) admission, but is not part of routine coagulation monitoring in many centers. We investigated the predictive ability of the laboratory parameters hemoglobin ( $\mathrm{Hb}$ ) and base excess (BE) upon admission, as well as the Injury Severity Score (ISS), to estimate FIB in major trauma patients.

Methods: In this retrospective study, major trauma patients (ISS $\geq 16)$ with documented FIB analysis upon ER admission were eligible for inclusion. FIB was correlated with $\mathrm{Hb}, \mathrm{BE}$ and ISS, alone and in combination, using regression analysis.
\end{abstract}

Results: A total of 675 patients were enrolled (median ISS 27). FIB upon admission correlated strongly with $\mathrm{Hb}$, $\mathrm{BE}$ and ISS. Multiple regression analysis showed that $\mathrm{Hb}$ and $\mathrm{BE}$ together predicted FIB (adjusted $\mathrm{R}^{2}=0.46$; $\left.\log _{e}(F I B)=3.567+0.223 . \mathrm{Hb}-0.007 . \mathrm{Hb}^{2}+0.044 . \mathrm{BE}\right)$, and predictive strength increased when ISS was included (adjusted $\mathrm{R}^{2}=0.51 ; \log _{\mathrm{e}}(\mathrm{FIB})=4.188+0.243 . \mathrm{Hb}-0.008 . \mathrm{Hb}^{2}+0.036 . \mathrm{BE}-0.031 . \mathrm{ISS}+0.0003 . \mathrm{ISS}^{2}$ ). Of all major trauma patients admitted with $\mathrm{Hb}<12 \mathrm{~g} / \mathrm{dL}, 74 \%$ had low $(<200 \mathrm{mg} / \mathrm{dL}) \mathrm{FIB}$ and $54 \%$ had critical $(<150 \mathrm{mg} / \mathrm{dL})$ FIB. Of patients admitted with $\mathrm{Hb}<10 \mathrm{~g} / \mathrm{dL}, 89 \%$ had low FIB and $73 \%$ had critical FIB. These values increased to $93 \%$ and $89 \%$, respectively, among patients with an admission $\mathrm{Hb}<8 \mathrm{~g} / \mathrm{dL}$. Sixty-six percent of patients with only a weakly negative $\mathrm{BE}(<-2 \mathrm{mmol} / \mathrm{L})$ showed low FIB. Of patients with $\mathrm{BE}<-6 \mathrm{mmol} / \mathrm{L}$ upon admission, $81 \%$ had low FIB and $63 \%$ had critical FIB. The corresponding values for $\mathrm{BE}<-10 \mathrm{mmol} / \mathrm{L}$ were $89 \%$ and $78 \%$, respectively.

Conclusions: Upon ER admission, FIB of major trauma patients shows strong correlation with rapidly obtainable, routine laboratory parameters such as $\mathrm{Hb}$ and $\mathrm{BE}$. These two parameters might provide an insightful and rapid tool to identify major trauma patients at risk of acquired hypofibrinogenemia. Early calculation of ISS could further increase the ability to predict FIB in these patients. We propose that FIB can be estimated during the initial phase of trauma care based on bedside tests.

\section{Introduction}

Trauma-induced coagulopathy (TIC) has been reported in 25 to $35 \%$ of all injured patients upon admission to the emergency room (ER) [1,2]. Established TIC strongly increases the risk of massive transfusion (MT), prolonged length of intensive care unit (ICU) and hospital stay, and mortality [1]. Importantly, coagulation factors do not decrease in a uniform manner in severely bleeding

\footnotetext{
* Correspondence: herbert.schoechl@auva.at

'Ludwig Boltzmann Institute for Experimental and Clinical Traumatology, AUVA Research Centre, Donaueschingenstrasse 13, 1200 Vienna, Austria Full list of author information is available at the end of the article
}

patients. Plasma fibrinogen (FIB) reaches critically low levels earlier than any other coagulation factor [3] and low FIB is almost always the primary coagulation factor deficiency during major bleeding, as shown for example in trauma [4] and postpartum hemorrhage (PPH) [5].

Fibrinogen plays a central role in primary and secondary hemostasis [6]. It has a high affinity for glycoprotein IIb/ IIIa receptors which are expressed on activated platelets and is therefore essential for platelet aggregation. Moreover, fibrinogen is a substrate of the coagulation process and precursor of the fibrin network. Low FIB has been associated with increased blood loss and/or transfusion

C Biomed Central

(C) 2013 Schlimp et al.; licensee BioMed Central Ltd. This is an open access article distributed under the terms of the Creative Commons Attribution License (http://creativecommons.org/licenses/by/2.0), which permits unrestricted use, distribution, and reproduction in any medium, provided the original work is properly cited. 
requirements in a number of settings, including cardiac surgery, PPH and trauma [7-11], and has recently been reported to worsen outcomes in trauma patients receiving MT [12]. Thus, early replacement of fibrinogen is beneficial in trauma patients experiencing severe bleeding [13-18], and the recent European trauma guidelines recommend a FIB threshold concentration for bleeding patients of 150 to $200 \mathrm{mg} / \mathrm{dL}$ as a trigger for replacement therapy [19].

In the AUVA Trauma Centre of Salzburg, rapid point-ofcare (POC) estimation of fibrin polymerization (that is via the FIBTEM assay on thromboelastometry (ROTEM)) has been established to diagnose fibrinogen deficiencies and to guide fibrinogen substitution in major trauma patients [10,14,15,20-22]. POC blood gas analyses and full blood cell counts are routinely performed in severe trauma patients upon admission to the ER. Furthermore, standard laboratory tests including prothrombin time (PT), activated partial thromboplastin time (aPTT) and FIB, are performed in the hospital's central laboratory with the highest priority. A major problem with these tests is the long turnaround time: the average time for results to reach the clinician is typically around 45 minutes and longer durations have been published [23,24]. Furthermore, PT and aPTT were principally designed for monitoring warfarin and heparin. For these reasons, coagulation management in our institution is based mainly on the results of POC tests, particularly ROTEM analysis (thrombelastography (TEG) could be a viable alternative to ROTEM). However, in many trauma centers, neither ROTEM nor TEG is routinely used for assessing trauma patients, and it is also common for FIB to be missing from routine coagulation assessment.

We therefore conducted a retrospective study to investigate the predictive ability of the laboratory parameters hemoglobin $(\mathrm{Hb})$ and base excess $(\mathrm{BE})$ to estimate FIB of major trauma patients upon admission to the ER. To increase the accuracy of these predictions, we included the Injury Severity Score (ISS) in the analyses.

\section{Material and methods}

The ethics committee of the federal state of Salzburg (Ehtikkommission für das Bundesland Salzburg) approved (Protocol: 415-EP/73/197-2013) this retrospective analysis of data from all major trauma patients (ISS $\geq 16$ ) admitted to the ER of the AUVA Trauma Centre, Salzburg, Austria, between January 2005 and December 2012 and waived the need for patients' informed consent.

The laboratory parameters of interest in this study, $\mathrm{Hb}$ $(\mathrm{g} / \mathrm{dL}), \mathrm{BE}(\mathrm{mmol} / \mathrm{L})$ and FIB $(\mathrm{mg} / \mathrm{dL}$, Clauss method) were documented with the time of admission in the electronic patient database of the hospital or the patient charts. We considered the main parameters for quick estimation of FIB in this study to be $\mathrm{Hb}$ and $\mathrm{BE}$. However, for the addition of a measure of injury severity, we also aimed to include ISS.

ISS, hospital mortality, sex and age were documented in the electronic ICU documentation (ICdoc) or, in cases where the patient was not admitted to the ICU, in the electronic patient database of the hospital. ISS was calculated according to the final diagnosis of all detected patient injuries at the end of stay.

\section{Statistical analysis}

Continuous study variables (FIB, $\mathrm{Hb}, \mathrm{BE}$, ISS and age) were analyzed for normal distribution by the KolmogorovSmirnov test. To detect differences between groups, either the Student's $t$ test or the Mann-Whitney $U$ test was performed, depending on the underlying distribution. Categorical variables were analyzed with Fisher's exact test. Overall group differences were compared by the Kruskal-Wallis or the chi-square test. A Spearman correlation analysis was performed to correlate $\mathrm{Hb}, \mathrm{BE}$ and ISS with FIB. Unless otherwise stated, data are presented as median (interquartile range (IQR)) for continuous variables, and as number (percentages) for categorical variables. Overall, a $P$ value $<0.05$ was considered significant for all statistical tests. Standard statistical calculations were performed using GraphPad Prism 5 (GraphPad Software, La Jolla, CA, USA).

A multivariate analysis was carried out to examine the ability of the parameters $\mathrm{Hb}, \mathrm{BE}$ and ISS to predict FIB. Linear regression was used to examine the relationship between all three parameters and FIB. Due to the slightly positively skewed distribution and issues of homoscedasticity, the regression analyses were performed with FIB on the log scale. Initially, the effect of each predictor variable upon FIB was examined separately, and the nature of the relationship between each predictor and the outcome was examined. If the relationship was found to be nonlinear, then squared terms for each predictor were introduced. Subsequently, the effect of each of the predictor variables was evaluated in combination using predetermined combinations of variables. The predictive ability of the models was assessed by the $R^{2}$ and adjusted $R^{2}$ statistics. Multivariate statistical calculations were performed using the statistical software package Stata 12.1 (StatCorp LP, College Station, TX, USA).

\section{Results}

A total of 680 major trauma patients with documented FIB analysis immediately after admission were identified. Of these, 675 were eligible for inclusion (three patients were excluded due to participation in another study, and a further two patients were excluded for nontraumarelated admission). ISS and $\mathrm{Hb}$ values were available for all 675 patients, BE for 576 patients only. 
Median ISS was 27 (20 to 38 IQR), median age was 45 (27 to 59 IQR) and 537 (79.6\%) patients were male. Overall in-hospital mortality of the study cohort was $15.7 \%(n=106)$. Patient characteristics were stratified according to ISS (Table 1).

\section{Correlation and multiple regression analysis}

When examined individually, all three variables $(\mathrm{Hb}, \mathrm{BE}$ and ISS) were strongly associated with FIB (Figure 1A to $1 \mathrm{C}$ ). We then examined the separate effect of each of the three predictor variables upon FIB. The results of these analyses are summarized in Table 2 . The strongest predictor was $\mathrm{Hb}\left(\mathrm{R}^{2}=0.40\right)$, followed by $\mathrm{BE}\left(\mathrm{R}^{2}=0.29\right)$; these parameters explained the largest proportion of the variation in fibrinogen values. The relationship between FIB and the predictor variables $\mathrm{Hb}$ and ISS were found to be nonlinear.

Subsequently, various combinations of variables were analyzed together in a series of multiple regression analyses. The results of these analyses are summarized in Table 3. Even after adjusting for the effects of the other variables each of the three variables remained statistically significant, suggesting that all three are independent predictors of FIB.

By analyzing different combinations of the three variables, the following models for the prediction of FIB were generated:

Model $1(\mathrm{Hb}, \mathrm{BE}) \log _{\mathrm{e}}(\mathrm{FIB})=3.567+0.223 . \mathrm{Hb}-$ 0.007. $\mathrm{Hb}^{2}+0.044 . \mathrm{BE}$

Model 2 (BE, ISS) $\log _{\mathrm{e}}(\mathrm{FIB})=6.129+0.056 . \mathrm{BE}-$ 0.034.ISS + 0.0003. ISS $^{2}$

Model $3(\mathrm{Hb}, \mathrm{ISS}) \log _{\mathrm{e}}(\mathrm{FIB})=3.609+0.301 . \mathrm{Hb}-$ $0.009 . \mathrm{Hb}^{2}-0.029 . \mathrm{ISS}+0.0002 . \mathrm{ISS}^{2}$

Model $4(\mathrm{Hb}, \mathrm{BE}, \mathrm{ISS}) \log _{\mathrm{e}}(\mathrm{FIB})=4.188+0.243 . \mathrm{Hb}-$ 0.008. $\mathrm{Hb}^{2}+0.036 . \mathrm{BE}-0.031 . \mathrm{ISS}+0.0003 . \mathrm{ISS}^{2}$

Model 1, including the two main variables to quickly calculate FIB, provides an adjusted $R^{2}$ value of 0.46 , suggesting that $46 \%$ of the variation in fibrinogen values can be explained by the combination of $\mathrm{Hb}$ and $\mathrm{BE}$ (Table 3). The model containing all three variables (Model 4) provides the highest predictive ability. The adjusted $R^{2}$ value from this model was 0.51 , suggesting that $51 \%$ of the variation in fibrinogen values can be explained by the combination of three predictor variables.

\section{Clinical applicability}

Overall, $74 \%$ of major trauma patients admitted with $\mathrm{Hb}<12 \mathrm{~g} / \mathrm{dL}$ had low $(<200 \mathrm{mg} / \mathrm{dL}) \mathrm{FIB}$, and critical $(<150 \mathrm{mg} / \mathrm{dL}) \mathrm{FIB}$ was observed in $54 \%$. Of patients admitted with $\mathrm{Hb}<10 \mathrm{~g} / \mathrm{dL}, 89 \%$ had low FIB and $73 \%$ had critical FIB. These values increased to $93 \%$ and $89 \%$, respectively, among patients with an admission $\mathrm{Hb}<8 \mathrm{~g} / \mathrm{dL}$. Sixty-six percent of patients with only a weakly negative $\mathrm{BE}(<-2 \mathrm{mmol} / \mathrm{L})$ showed low FIB. Of patients with $\mathrm{BE}<-6 \mathrm{mmol} / \mathrm{L}$ upon admission, $81 \%$ had low FIB and $63 \%$ had critical FIB. Changing the criterion to an admission $\mathrm{BE}<-10 \mathrm{mmol} / \mathrm{L}$ produced a low FIB rate of $89 \%$ and a critical FIB rate of $78 \%$. Considering the ISS, $56 \%$ of major trauma patients with a score $\geq 16$ showed low FIB. The corresponding percentages among patients with ISS $\geq 25, \geq 35$ and $\geq 50$ were $68 \%, 88 \%$ and $93 \%$, respectively. Critically low FIB was observed in $67 \%$ of patients with ISS $\geq 35$ and in $74 \%$ of those with ISS $\geq 50$.

Based on results from the above evaluation, we designed charts to rapidly, easily and accurately identify those patients at risk of low $(<200 \mathrm{mg} / \mathrm{dL})$ and critical ( $<150 \mathrm{mg} / \mathrm{dL})$ FIB levels.

For each of the three variables patients were arranged into the following categories:

$\mathrm{Hb}(\mathrm{g} / \mathrm{dL})<8.0 ; 8.0$ to $9.9 ; 10.0$ to $11.9 ; \geq 12.0$

$\mathrm{BE}(\mathrm{mmol} / \mathrm{L})<-10 ;-10.0$ to $-6.1 ;-6.0$ to $-2.1 ; \geq-2.0$

ISS 16 to $24 ; 25$ to $34 ; 35$ to $49 ; 50$ to 75

FIB was found to significantly change according to each category (Figure $2 \mathrm{~A}$ to $2 \mathrm{C}$ ).

Table 1 Patient demographics stratified according to Injury Severity Score.

\begin{tabular}{|c|c|c|c|c|c|}
\hline & ISS 16-24 & ISS 25-34 & ISS $35-49$ & ISS $50-75$ & $\begin{array}{c}P \text { value for all } 4 \text { group } \\
\text { differences }\end{array}$ \\
\hline Patients $\mathrm{n}$ ( $\%$ of total) & $242(35.9 \%)$ & $249(36.9 \%)$ & $97(14.4 \%)$ & $87(12.9 \%)$ & $\mathrm{N} / \mathrm{A}$ \\
\hline Age (range) & $42.5(26-56)$ & $47(29.5-60) n s$ & $45(24-59) n s$ & $42(25-59) n s$ & nsKruskal- Wallis \\
\hline Male $n$ (\% of ISS group) & $200(82.6 \%)$ & $195(78.3 \%) n s$ & $76(78.4 \%) n s$ & $66(75.9 \%) n s$ & nsChi-square \\
\hline $\begin{array}{l}\text { Mortality } n \text { ( } \% \text { of ISS } \\
\text { group) }\end{array}$ & $5(2.1 \%)$ & $32(12.9 \%)^{* * *}$ & $27(27.8 \%)^{* *}$ & $42(48.3 \%)^{* *}$ & ${ }^{* * *}$ Chi-square \\
\hline FIB mg/dL (IQR) & $235(182.5-286.3)$ & $191.0(143-240)^{* * *}$ & $134(94.5-185.5)^{* * *}$ & $114(69-156)^{*}$ & ${ }^{* *}$ Kruskal- Wallis \\
\hline $\mathrm{Hb}$ g/dL (IQR) & $13.0(11.7-14.2)$ & $12.3(10.6-13.7)^{* * *}$ & $10.9(8.4-13.0)^{* * *}$ & $9.6(7.0-11.6)^{* *}$ & ${ }^{* *}$ Kruskal- Wallis \\
\hline BE mmol/L (IQR) & $\begin{array}{c}-2.6(-4.5 \text { to } \\
-1.4)\end{array}$ & $-3.7 \underset{* * *}{(-6.2 \text { to }}-2.1)$ & $-5.7 \underset{* * *}{(-8.5 \text { to }}-2.9)$ & $-7.1 \underset{* *}{(-10.9}$ to -4.6$)$ & ${ }^{* *}$ Kruskal- Wallis \\
\hline
\end{tabular}

ns, not significant, ${ }^{*} P<0.05$, ${ }^{*} P<0.01$, ${ }^{* * *} P<0.001$, significance values for comparison with previous group. BE, base excess; FlB, plasma fibrinogen; Hb, hemoglobin; IQR, interquartile range; ISS, Injury Severity Score. 


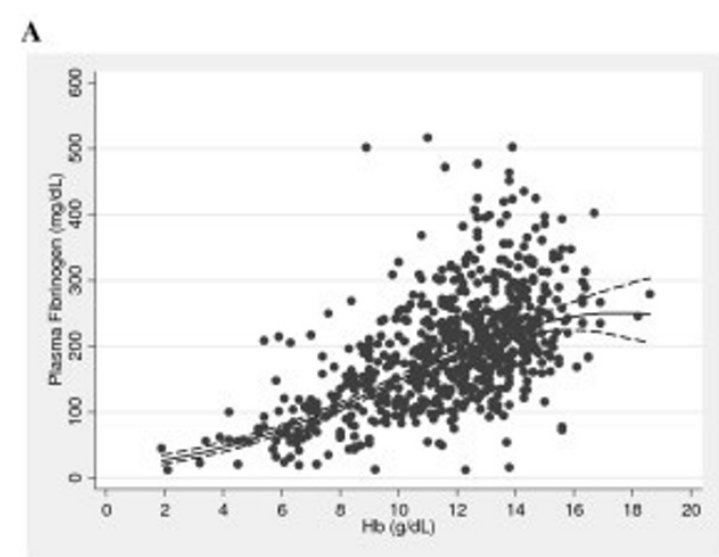

B

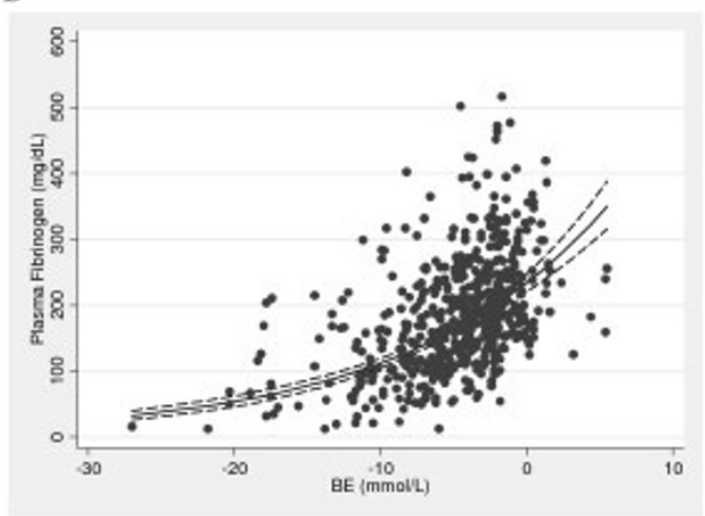

C

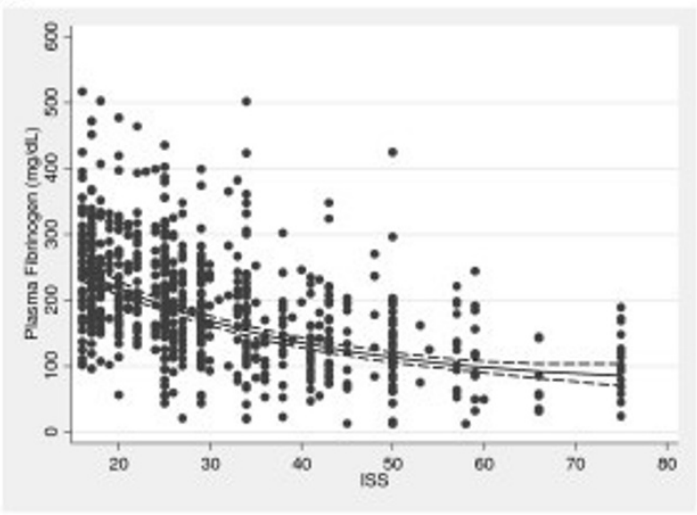

Figure 1 Correlation between FIB and $\mathrm{Hb}, \mathrm{BE}$ or ISS. Plasma fibrinogen concentration $(F I B, m g / d L)$ versus $(A)$ hemoglobin $(\mathrm{Hb}$, $\mathrm{g} / \mathrm{dL}),(\mathbf{B})$ base excess $(B E, \mathrm{mmol} / \mathrm{L})$ and $(\mathbf{C})$ Injury Severity Score (ISS). The fitted regression line (solid) is shown along with a corresponding 95\% confidence interval (dotted lines).

We then combined two variables together at a time and calculated the resulting median FIB level for each new group (Figure 3 ). In this way, we were able to easily identify patients at risk of low or critical FIB, when combining the rapidly obtainable, routine laboratory parameters $\mathrm{Hb}$ and $\mathrm{BE}$ upon admission (Figure $3 \mathrm{~A}$ ). Combining ISS with either $\mathrm{Hb}$ or $\mathrm{BE}$ can be used in the same way (Figures $3 \mathrm{~B}$ and $3 \mathrm{C}$ ). In each category, the observed percentage of patients with adequate FIB $(\geq 200 \mathrm{mg} / \mathrm{dL}$, green), low FIB (199 to $150 \mathrm{mg} / \mathrm{dL}$, orange) and critical FIB $(<150 \mathrm{mg} / \mathrm{dL}$, red) was identified and is shown in Figures 4 to 6.

\section{Discussion}

In the current study, we found that FIB concentration upon admission to the ER is strongly correlated with the severity of injury, blood loss, dilution and shock. The statistical analysis suggests that $\mathrm{Hb}, \mathrm{BE}$ and ISS, either alone or in combination, allow estimation of FIB in major trauma patients upon admission. Together, these three parameters account for approximately 51\% of the variability in the observed fibrinogen concentration values. Furthermore, $\mathrm{Hb}$ and $\mathrm{BE}$ in combination (and alternatively/additionally ISS) could be used to rapidly identify major trauma patients at risk of low $(<200 \mathrm{mg} / \mathrm{dL})$ and critical $(<150 \mathrm{mg} / \mathrm{dL})$ FIB concentration.

The most striking finding of the current study is that $51 \%$ of the variability in FIB can be explained by $\mathrm{Hb}, \mathrm{BE}$ and ISS. Shock and substantial tissue injury have been identified as important drivers of TIC, resulting in a profibrinolytic state via the activation of the protein $C$ pathway $[1,19,25,26]$. Our findings are a proof of the concept that TIC (considered to be a distinct, multifactorial, primary disorder, secondarily amplified by consumption, loss and dilution) requires two conditions: hemodynamic instability (that is shock) and sufficiently massive tissue damage. Therefore, besides blood loss and dilution, both tissue trauma and hypoperfusion independently decrease FIB concentration.

Fibrinogen is an important coagulation factor, acting not only as the precursor of fibrin, the end product of the coagulation process [6,27], but also as a key ligand between activated platelets [28]. In several clinical studies in cardiac surgery and $\mathrm{PPH}$, fibrinogen deficiency was associated with increased blood loss and transfusion requirements [7-9]. For trauma patients, low fibrinogen on admission to the ER was associated with increased transfusion requirements and mortality $[10,11]$. These data have been confirmed recently by further analyses of the PROMMTT study [29].

There are many reasons for decreased FIB concentration, including easily detectable variables such as blood loss, dilution, hypothermia and acidosis, and harder to detect variables such as consumption, hyperfibrinolysis and measurement-specific variability. In severe bleeding during elective surgery, FIB reaches critically low levels earlier than any other coagulation protein [3]. In light of the threshold levels used by Hiippala et al. (100 mg/dL), it may be speculated that current recommended thresholds 
Table 2 Effect of hemoglobin, base excess and Injury Severity Score upon plasma fibrinogen.

\begin{tabular}{llcccc}
\hline Variable & Term & Ratio $(\mathbf{9 5 \%} \mathrm{Cl})$ & $\boldsymbol{P}$ value & $\mathbf{R}^{\mathbf{2}}$ & $\mathbf{A d j .} \mathbf{R}^{\mathbf{2}}$ \\
\hline $\mathrm{Hb}^{*}$ & Linear term & $4.96(3.47,7.11)$ & $<0.001$ & 0.40 & 0.40 \\
& Squared term & $0.80(0.73,0.86)$ & & & \\
$\mathrm{BE}^{*}$ & Linear term & $1.44(1.38,1.51)$ & $<0.001$ & 0.29 & 0.29 \\
$\mathrm{ISS}^{* *}$ & Linear term & $0.70(0.62,0.79)$ & $<0.001$ & 0.26 & 0.25 \\
& Squared term & $1.02(1.00,1.03)$ & & & \\
\hline
\end{tabular}

*Ratios reported for a 5-unit increase in predictor variable; ${ }^{* *}$ ratios reported for a 10-unit increase in predictor variable. Adj., adjusted; $\mathrm{BE}$, base excess; $\mathrm{Hb}$, hemoglobin; ISS, Injury Severity Score.

levels (150 to $200 \mathrm{mg} / \mathrm{dL}$ ) could be reached with a smaller volume of blood loss.

Rourke et al. showed that increasing shock severity was associated with a drop in FIB $(n=517)$ [16]. The same group recently found in a study of 300 patients that TIC, as defined by a calculated prothrombin time ratio $>1.2$, is associated with a low mean FIB of $96 \mathrm{mg} / \mathrm{dL}$, as compared

Table 3 Multiple regression models showing the combined effect of hemoglobin, base excess and Injury Severity Score upon plasma fibrinogen.

\begin{tabular}{|c|c|c|c|c|c|c|}
\hline Model & Variable & Term & $\begin{array}{c}\text { Ratio }(95 \% \\
\text { Cl) }\end{array}$ & $\begin{array}{c}P \\
\text { value }\end{array}$ & $\mathrm{R}^{2}$ & $\begin{array}{l}\text { Adj. } \\
\mathrm{R}^{2}\end{array}$ \\
\hline \multirow[t]{3}{*}{1} & $\mathrm{Hb}^{*}$ & Linear term & $\begin{array}{c}3.21(2.20 \\
4.68)\end{array}$ & $<0.001$ & 0.47 & 0.46 \\
\hline & & $\begin{array}{l}\text { Squared } \\
\text { term }\end{array}$ & $\begin{array}{c}0.84(0.78 \\
0.92)\end{array}$ & $<0.001$ & & \\
\hline & $\mathrm{BE}^{*}$ & Linear term & $\begin{array}{c}1.25(1.19 \\
1.30)\end{array}$ & & & \\
\hline \multirow[t]{3}{*}{2} & $\mathrm{BE}^{*}$ & Linear term & $\begin{array}{c}1.33(1.26 \\
1.39)\end{array}$ & $<0.001$ & 0.38 & 0.38 \\
\hline & ISS** & Linear term & $\begin{array}{c}0.71(0.63 \\
0.80)\end{array}$ & $<0.001$ & & \\
\hline & & $\begin{array}{l}\text { Squared } \\
\text { term }\end{array}$ & $\begin{array}{c}1.03(1.01 \\
1.04)\end{array}$ & & & \\
\hline \multirow[t]{4}{*}{3} & $H b^{*}$ & Linear term & $\begin{array}{c}4.49(3.19 \\
6.34)\end{array}$ & $<0.001$ & 0.47 & 0.47 \\
\hline & & $\begin{array}{l}\text { Squared } \\
\text { term }\end{array}$ & $\begin{array}{c}0.79(0.73 \\
0.86)\end{array}$ & & & \\
\hline & ISS** & Linear term & $\begin{array}{c}0.75(0.68 \\
0.83)\end{array}$ & $<0.001$ & & \\
\hline & & $\begin{array}{l}\text { Squared } \\
\text { term }\end{array}$ & $\begin{array}{c}1.02(1.01 \\
1.04)\end{array}$ & & & \\
\hline \multirow[t]{5}{*}{4} & $\mathrm{Hb}^{*}$ & Linear term & $\begin{array}{c}3.37(2.34 \\
4.87)\end{array}$ & $<0.001$ & 0.51 & 0.51 \\
\hline & & $\begin{array}{l}\text { Squared } \\
\text { term }\end{array}$ & $\begin{array}{c}0.83(0.76 \\
0.90)\end{array}$ & & & \\
\hline & $\mathrm{BE}^{*}$ & Linear term & $\begin{array}{c}1.20(1.14 \\
1.25)\end{array}$ & $<0.001$ & & \\
\hline & ISS** & Linear term & $\begin{array}{c}0.73(0.66 \\
0.82)\end{array}$ & $<0.001$ & & \\
\hline & & $\begin{array}{l}\text { Squared } \\
\text { term }\end{array}$ & $\begin{array}{c}1.03(1.02 \\
1.04)\end{array}$ & & & \\
\hline
\end{tabular}

*Ratios reported for a 5-unit increase in predictor variable; ** ratios reported for a 10-unit increase in predictor variable. Adj., adjusted; $\mathrm{BE}$, base excess; $\mathrm{Cl}$ confidence interval; $\mathrm{Hb}$, hemoglobin; ISS, Injury Severity Score. to $220 \mathrm{mg} / \mathrm{dL}$ in noncoagulopathic patients [30]. This suggests that PT is a predictor of coagulopathy caused by low fibrinogen. Floccard et al. also reported that in blood samples drawn immediately upon admission from trauma patients with ISS $>40$, median FIB concentration was 120 $\mathrm{mg} / \mathrm{dL}$ [31]. Dilutional coagulopathy was unlikely, as patients did not receive significant amounts of fluid prior to blood collection; therefore, low observed FIB levels could be due to profibrinolytic breakdown and/or consumption. These results are in agreement with those from a study by Tauber et al. of coagulation factor levels in 334 trauma patients on admission to the ER, in which FIB concentration was significantly reduced (median $160 \mathrm{mg} /$ $\mathrm{dL}$ ) in patients with ISS $>50$ [11]. This is similar to our results, where we observed a median FIB of $114 \mathrm{mg} / \mathrm{dL}$ for all patients with ISS $>50$, and higher median FIB concentrations in patient groups with ISS 35 to 49 (median $134 \mathrm{mg} / \mathrm{dL}$ ), ISS 25 to 34 (median $191 \mathrm{mg} / \mathrm{dL}$ ) and ISS 16 to 24 (median $235 \mathrm{mg} / \mathrm{dL}$ ) (Table 1 ).

Fluid therapy plays an essential role in restoring intravascular volume in massive hemorrhage. The main side effect of volume resuscitation using crystalloids is dilutional coagulopathy. Additionally, artificial colloids, such as starches and gelatins, impair fibrin polymerization [32]. Data from 8,724 patients from the German trauma registry revealed that early traumatic coagulopathy was associated with the amount of intravenous fluids administered preclinically [2]. Floccard et al., who studied FIB levels at the trauma scene and in the ER, observed a decrease in median FIB from 260 to $210 \mathrm{mg} / \mathrm{dL}$ in patients receiving median $500 \mathrm{~mL}$ of prehospital fluid [31]. In more severely injured patients (ISS >40) receiving 1,250 $\mathrm{mL}$ of prehospital fluid, a FIB of $120 \mathrm{mg} / \mathrm{dL}$ was measured. The fall in FIB levels observed between the trauma scene and admission to the ER may be explained in part by the administration of intravenous fluids. The impact of blood loss and subsequent dilution due to prehospital fluid administration can be detected in our study, as $\mathrm{Hb}$ is directly proportional to FIB (Table 2; Figure 1A); this may explain up to $40 \%$ of the variation in FIB observed in the studied patients.

In the current study, we have shown that more negative $\mathrm{BE}$ values are associated with lower FIB levels. Although current experimental models of acidosis are insufficient to explain trauma and shock-induced acidosis, Martini et al. showed that, in a pig model, $\mathrm{HCl}$-induced acidosis resulted in premature degradation of fibrinogen [33]. Furthermore, White et al. observed reduced fibrinogen with increasing severity of shock [34]. This suggests a possible cause for the low FIB values in patients with more negative $\mathrm{BE}$ values in this study.

Increased consumption of coagulation factors at the site of injury may contribute to lower FIB levels in trauma patients. In patients with severe traumatic brain 

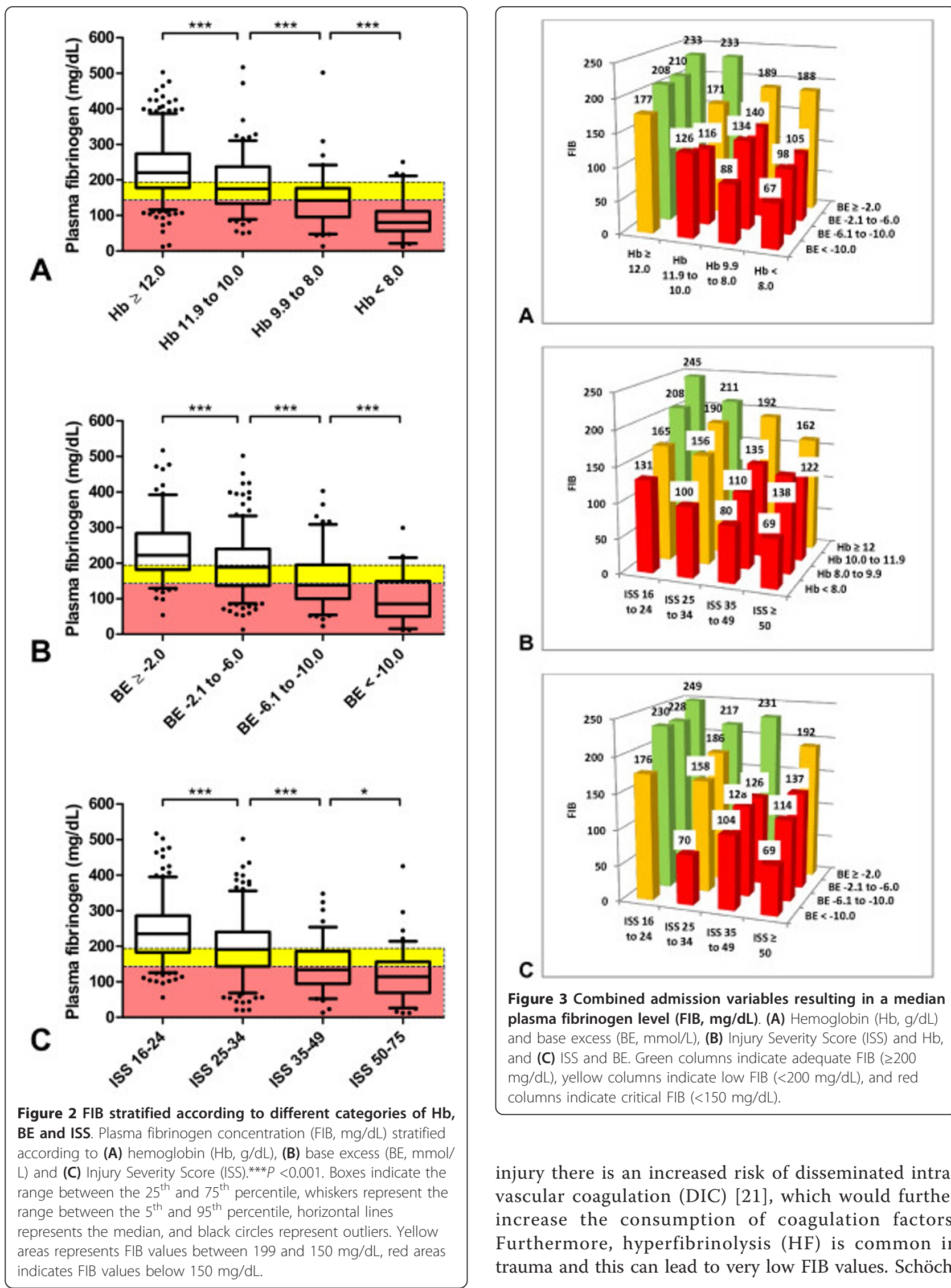

Figure 3 Combined admission variables resulting in a median plasma fibrinogen level (FIB, mg/dL). (A) Hemoglobin ( $\mathrm{Hb}, \mathrm{g} / \mathrm{dL}$ ) and base excess (BE, mmol/L), (B) Injury Severity Score (ISS) and $\mathrm{Hb}$, and (C) ISS and BE. Green columns indicate adequate FIB $(\geq 200$ $\mathrm{mg} / \mathrm{dL})$, yellow columns indicate low FIB $(<200 \mathrm{mg} / \mathrm{dL})$, and red columns indicate critical FIB $(<150 \mathrm{mg} / \mathrm{dL})$.

injury there is an increased risk of disseminated intravascular coagulation (DIC) [21], which would further increase the consumption of coagulation factors. Furthermore, hyperfibrinolysis (HF) is common in trauma and this can lead to very low FIB values. Schöchl 


\begin{tabular}{|c|c|c|c|c|c|c|c|c|c|c|}
\hline \multicolumn{6}{|c|}{$B E \geq-2$} & \multicolumn{5}{|c|}{ BE -2.1 to -6} \\
\hline $100 \%$ & & & & & & $100 \%$ & & & & \\
\hline $80 \%$ & & & & & & $80 \%$ & & & & \\
\hline $60 \%$ & & & & & Ecritical FIB & $60 \%$ & & & & - critical FIB \\
\hline $40 \%$ & & & & & (<150 mg/dL) & $40 \%$ & & & & (<150 mg/dL) \\
\hline $20 \%$ & & & & & $\begin{array}{l}\text { "elow FIB (150- } \\
199 \mathrm{mg} / \mathrm{dL})\end{array}$ & $20 \%$ & & & & $\begin{array}{l}=\text { low FIB (150- } \\
199 \mathrm{mg} / \mathrm{dL})\end{array}$ \\
\hline $0 \%$ & $\begin{array}{l}\mathrm{Hb} \geq \\
12.0\end{array}$ & $\begin{array}{l}\mathrm{Hb} \\
11.9 \\
\text { to } \\
10.0\end{array}$ & $\begin{array}{l}\mathrm{Hb} 9.9 \\
\text { to } 8.0\end{array}$ & & $\begin{array}{r}=\text { Adequate FIB } \\
(\geq 200 \mathrm{mg} / \mathrm{dL})\end{array}$ & $0 \%$ & $\begin{array}{l}\mathrm{Hb} \geq \\
12.0\end{array}$ & $\begin{array}{c}\mathrm{Hb} \\
11.9 \\
\text { to } \\
10.0\end{array}$ & $\begin{array}{l}\mathrm{Hb} 9.9 \mathrm{Hb}< \\
\text { to } 8.08 .0\end{array}$ & $\begin{array}{l}=\text { Adequate FIB } \\
(\geq 200 \mathrm{mg} / \mathrm{dL})\end{array}$ \\
\hline & & & $3 E-6.1$ & to -1 & & & & & $B E<-10$ & \\
\hline $100 \%$ & & & & & & $100 \%$ & & & & \\
\hline $80 \%$ & & & & & & $80 \%$ & & & & \\
\hline $60 \%$ & & & & & m critical FIB & $60 \%$ & & & & critical FIB \\
\hline $40 \%$ & & & & & (<150 mg/aL) & $40 \%$ & & & & (<150 mg/du) \\
\hline $20 \%$ & & & & & $\begin{array}{l}\text { low FlB (150- } \\
199 \mathrm{mg} / \mathrm{dL})\end{array}$ & $20 \%$ & & & & $\begin{array}{l}\text { low FlB (150- } \\
199 \mathrm{mg} / \mathrm{dL} \text { ) }\end{array}$ \\
\hline $0 \%$ & $\begin{array}{l}\mathrm{Hb} \geq \\
12.0\end{array}$ & $\begin{array}{c}\mathrm{Hb} \\
11.9 \\
\text { to } \\
10.0\end{array}$ & $\begin{array}{l}\mathrm{Hb} 9.9 \\
\text { to } 8.0\end{array}$ & $\begin{array}{c}\mathrm{Hb}< \\
8.0\end{array}$ & $\begin{array}{r}\text { Adequate FIB } \\
(\geq 200 \mathrm{mg} / \mathrm{dL})\end{array}$ & $0 \%$ & $\begin{array}{l}\mathrm{Hb} \geq \\
12.0\end{array}$ & $\begin{array}{c}\mathrm{Hb} \\
11.9 \\
\text { to } \\
10.0\end{array}$ & $\begin{array}{l}\mathrm{Hb} 9.9 \mathrm{Hb}< \\
\text { to } 8.08 .0\end{array}$ & $\begin{array}{r}\text { Adequate FIB } \\
(\geq 200 \mathrm{mg} / \mathrm{dL})\end{array}$ \\
\hline
\end{tabular}

et al. observed FIB levels of $80 \pm 40 \mathrm{mg} / \mathrm{dL}$ in 33 trauma patients with established HF diagnosed with ROTEM [20]. Cotton et al. reported a median FIB value of 55 ( 52 to $219 \mathrm{IQR}$ ) $\mathrm{mg} / \mathrm{dL}$ in 41 patients with $\mathrm{HF}$, as diagnosed by TEG [35]. Despite resulting in low FIB values, HF cannot be detected directly by standard laboratory parameters alone [36]. In our current study, HF could have led to some extreme outliers with very low FIB values, even in patient groups not usually at risk of critical FIB levels (Figure 2).

When comparing FIB across different studies, it has to be taken into account that there are more than 60 different ways of measuring fibrinogen concentration, including numerous variations of the von Clauss method [37]. This introduces many factors that may affect the measured FIB, including the type of device, software, readout method, activators or calibration. Furthermore, it has been observed that the presence of artificial colloids (for example dextran or hydroxyethyl starch (HES)) significantly raises FIB measured using the PT-derived and von Clauss methods to levels above those predicted by the dilutional effect [38]. Thus, when high volumes of synthetic colloids are used during MT, hypofibrinogenemia may potentially be overlooked. This possibility has been confirmed by Adam et al., who reported that photo-optical methods significantly overestimate FIB in blood diluted with HES [39]. These studies showed that FIB was overestimated by $>50 \%$ and $>100 \%$ with $30 \%$ and $50 \%$ dilution, respectively. Notably, in this context the concentration of HES appears to be more important than molecular size $[39,40]$.

Data showing that fibrinogen supplementation improves survival in trauma patients are limited. However, experimental and initial clinical studies have reported promising outcomes following replacement of fibrinogen as the initial step in managing TIC $[13,15,41,42]$. Stinger et al. were the 


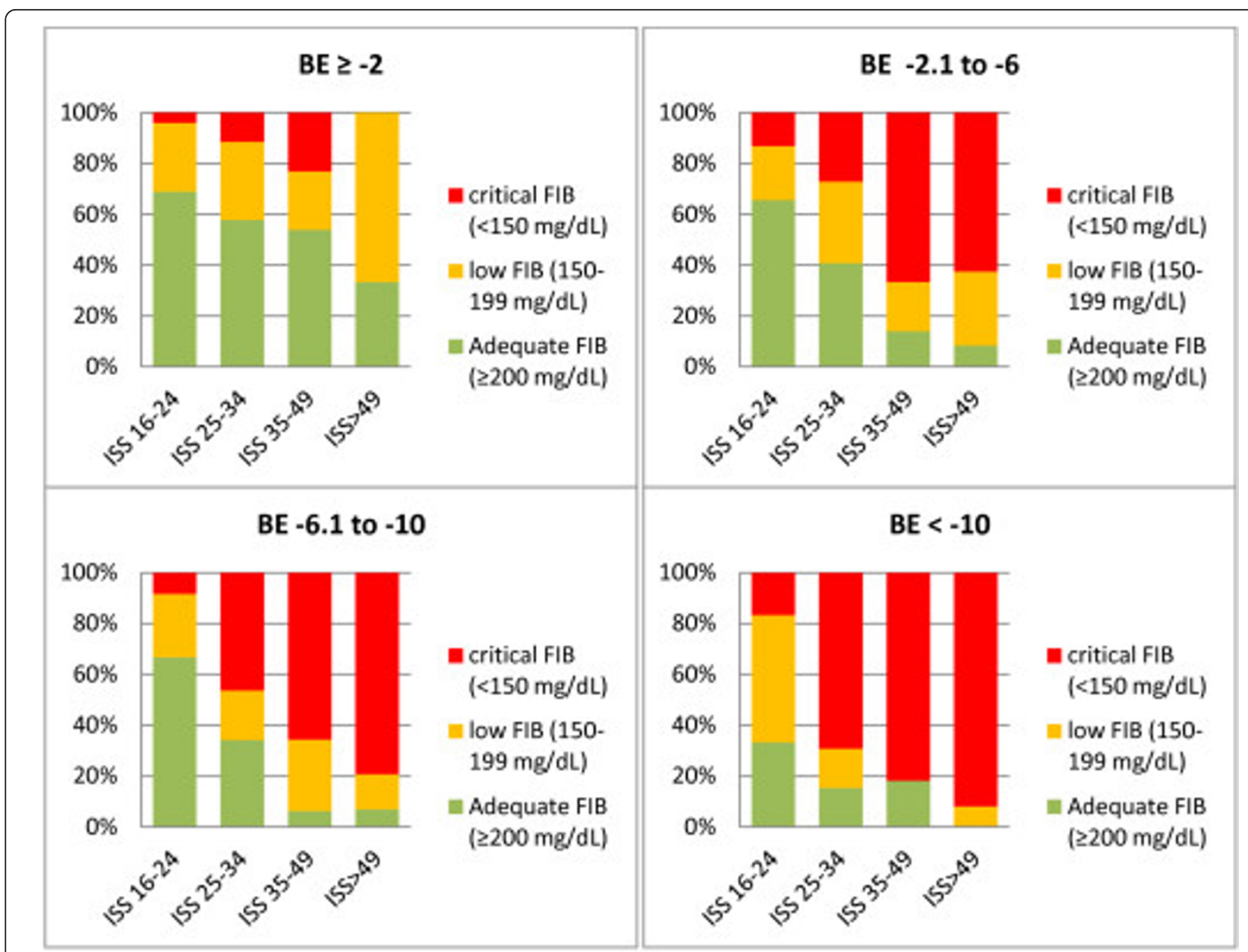

Figure 5 Percentage of patients with adequate, low and critical FIB stratified according to ISS and BE. Observed percentage of patients with adequate plasma fibrinogen concentration (FIB) ( $\geq 200 \mathrm{mg} / \mathrm{dL}$, green), low FIB (199 to $150 \mathrm{mg} / \mathrm{dL}$, yellow) and critical FlB $(<150 \mathrm{mg} / \mathrm{dL}$, red) when combining the admission variables Injury Severity Score (ISS) and base excess (BE, mmol/L).

first to show that a high ratio of red blood cells (RBCs) and fibrinogen resulted in improved outcomes [13]. Currently there are three potential sources of fibrinogen replacement therapy: therapeutic plasma (such as fresh frozen plasma (FFP)), cryoprecipitate and fibrinogen concentrate (FC). When using FFP, high-volume transfusion is necessary to provide sufficient increase in FIB. Larger and more rapid increases can be achieved using either cryoprecipitate or FC. However, cryoprecipitate contains variable quantities of fibrinogen, it must be thawed before use, and there have been significant safety concerns regarding the use of this product, mainly relating to a lack of viral inactivation. In contrast, FC is rapidly available, contains a high and standardized amount of fibrinogen, and is virally inactivated. In most European countries, cryoprecipitate is no longer used, and instead FC is available, delivering consistent amounts of fibrinogen [43]. Currently, a randomized pilot study in trauma patients is exploring the use of FC in the prehospital area [44].
The main limitation of the present study is its retrospective, uncontrolled nature. For example, we were not able to identify co-medications or comorbidities that could have influenced test results. Furthermore, we did not document hypothermia, which has been shown to influence fibrinogen synthesis in the liver [33]. However, this seems to be of greater importance for a longer observation period rather than upon ER admission. We also did not document preclinical fluid therapy, which might significantly influence TIC [2] and therefore FIB upon admission. However, we speculate that the admission parameter $\mathrm{Hb}$ indirectly includes the influence of preclinical fluid therapy on FIB levels. The multiple regression model of $\mathrm{Hb}, \mathrm{BE}$ and ISS explains around $51 \%$ of the variation observed in admission FIB. While the remaining variation is still unexplained by these variables, estimation of FIB through $\mathrm{Hb}, \mathrm{BE}$ and ISS seems acceptable and inclusion of further variables is unlikely to substantially improve prediction. A high 


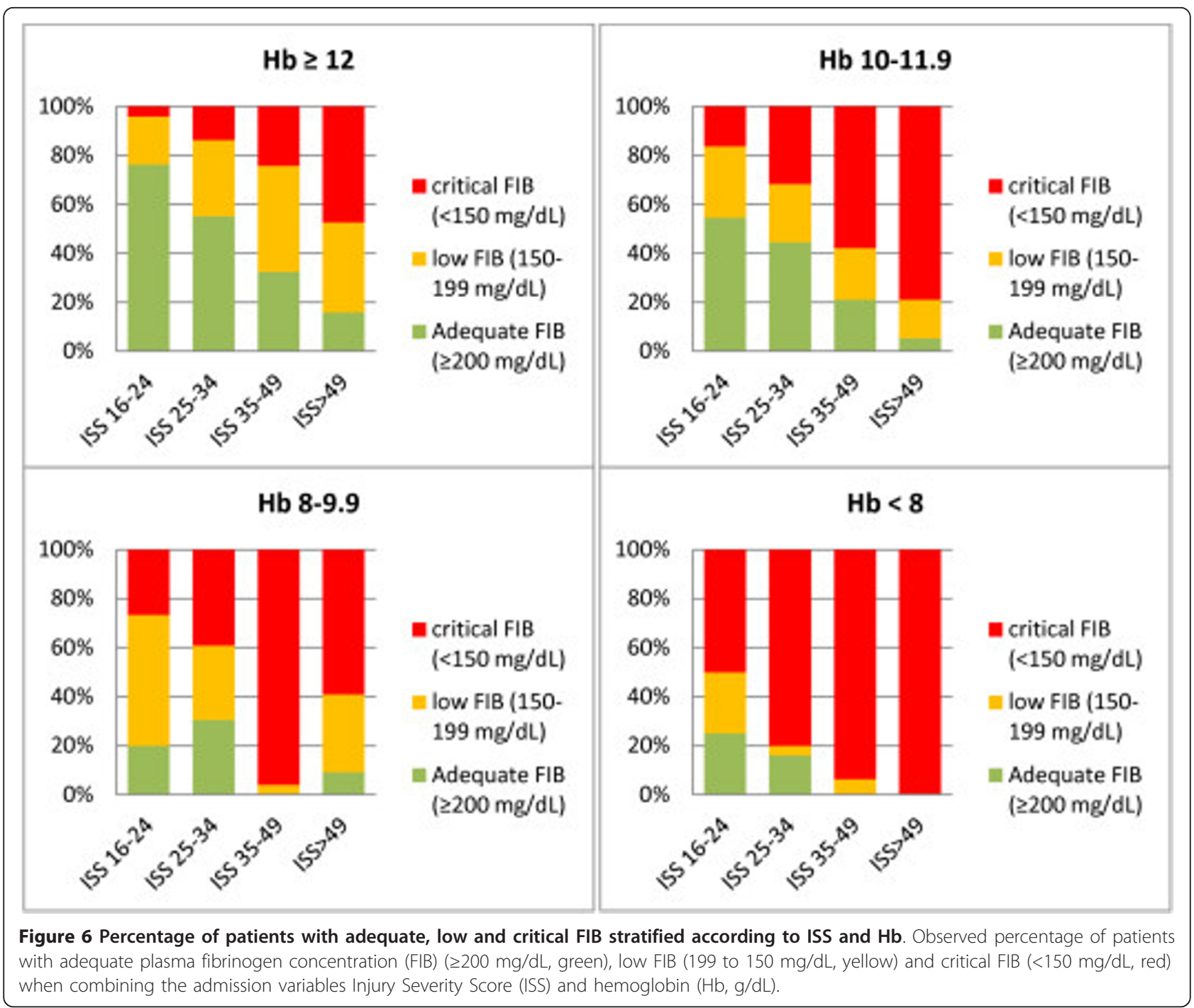

percentage of variation may arise from the normal physiological variation seen in human FIB values (200 to $450 \mathrm{mg} / \mathrm{dL}$ ) [10]. Patients with high normal baseline FIB values will tolerate much higher blood loss and dilution before FIB falls to critical levels, as compared to patients in the lower range of normal baseline values, in whom even a little hemodilution may induce dilutional coagulopathy [45]. Another consideration is that ISS is normally calculated at the end of stay, limiting the possibility of using this parameter for an early estimate of FIB. However, the ISS was developed in 1974 when trauma scans were not universally available [46]. Nowadays, practically all trauma centers in industrialized countries are equipped with computed tomography (CT) scanners, enabling important injuries to be diagnosed within a couple of minutes. Thus, an early estimation of ISS could conceivably be used for estimating FIB. Finally, we only included patients with blunt trauma. Therefore, the results of the current study provide FIB estimation for blunt injury only and will need to be confirmed in other trauma settings.

\section{Conclusions}

Upon ER admission, FIB of major trauma patients shows strong correlations with rapidly obtainable, routine laboratory parameters such as $\mathrm{Hb}$ and BE. These two parameters might provide an insightful and rapidly available tool to identify major trauma patients at risk of acquired hypofibrinogenemia. Early calculation of ISS can further increase the ability to predict FIB in these patients. We propose that FIB can be estimated during the initial phase of trauma care based on bedside tests.

\section{Key messages}

- Plasma fibrinogen of major trauma patients shows strong correlation with rapidly obtainable, routine 
laboratory parameters such as hemoglobin and base excess, upon admission to the emergency room.

- Based on clinical data, these two parameters might provide an insightful and rapidly available tool to identify major trauma patients at risk of acquired hypofibrinogenemia.

- Early calculation of Injury Severity Score can further increase the ability to predict plasma fibrinogen in these patients.

\begin{abstract}
Abbreviations
aPTT: activated partial thromboplastin time; BE: base excess; CT: computed tomography; DIC: disseminated intravascular coagulation; ER: emergency room; FC: fibrinogen concentrate; FFP: fresh frozen plasma; FIB: plasma fibrinogen; Hb: hemoglobin; HF: hyperfibrinolysis; HES: hydroxyethyl starch; ICU: intensive care unit; IQR: interquartile range; ISS: Injury Severity Score; MT: massive transfusion; POC: point-of-care; PPH: postpartum hemorrhage; PT: prothrombin time; RBCs: red blood cells; ROTEM: thromboelastometry; TEG: thrombelastography; TIC: trauma-induced coagulopathy.

\section{Competing interests}

Christoph Schlimp has received research support from CSL Behring. Wolfgang Voelckel declares no conflicts of interest. Kenji Inaba declares no conflicts of interest. Marc Maegele declares no conflicts of interest. Martin Ponschab declares no conflicts of interest. Herbert Schöchl has received speaker honoraria and research support from CSL Behring.
\end{abstract}

\section{Authors' contributions}

CJS and HS conceived the study design, collected, analyzed and interpreted the data, performed the statistical analysis and wrote the manuscript. MP contributed substantially to collecting and interpreting the data and critically revised the manuscript for important intellectual content. WV, KI and MM contributed substantially to interpreting the data and critically revised the manuscript for important intellectual content. All authors read and approved the final manuscript.

\section{Acknowledgements}

The authors would like to thank Dr Cristina Solomon and Mr Gerald Hochleitner for their useful comments during the preparation of the manuscript. Statistical and editorial assistance was provided by medical writers from Meridian HealthComms. Financial support for this assistance was provided by CSL Behring.

\section{Authors' details}

'Ludwig Boltzmann Institute for Experimental and Clinical Traumatology, AUVA Research Centre, Donaueschingenstrasse 13, 1200 Vienna, Austria. ${ }^{2}$ Department of Anaesthesiology and Intensive Care Medicine, AUVA Trauma Centre, Dr. Franz Rehrl Platz 5, 5020 Salzburg, Austria. ${ }^{3}$ Department of Surgery, Los Angeles County and University of Southern California Medical Center, 2051 Marengo Street, Los Angeles, CA 90033, USA. ${ }^{4}$ Department of Trauma and Orthopedic Surgery, Institute for Research in Operative Medicine (IFOM), University of Witten/Herdecke, Cologne-Merheim Medical Center (CMMC), Ostmerheimerstrasse 200, 51109 Cologne, Germany. ${ }^{5}$ Department of Anaesthesiology and Intensive Care Medicine, AUVA Trauma Centre, Garnisonstrasse 7, 4017 Linz, Austria.

Received: 28 March 2013 Revised: 24 May 2013 Accepted: 12 July 2013 Published: 12 July 2013

\section{References}

1. Brohi $\mathrm{K}$, Singh J, Heron M, Coats T: Acute traumatic coagulopathy. J Trauma 2003, 54:1127-1130.

2. Maegele M, Lefering R, Yucel N, Tjardes T, Rixen D, Paffrath T, Simanski C, Neugebauer E, Bouillon B: Early coagulopathy in multiple injury: an analysis from the German Trauma Registry on 8724 patients. Injury 2007, 38:298-304.

3. Hiippala ST, Myllyla GJ, Vahtera EM: Hemostatic factors and replacement of major blood loss with plasma-poor red cell concentrates. Anesth Analg 1995, 81:360-365.
4. Chambers LA, Chow SJ, Shaffer LE: Frequency and characteristics of coagulopathy in trauma patients treated with a low- or high-plasmacontent massive transfusion protocol. Am J Clin Pathol 2011, 136:364-370.

5. Solomon C, Collis RE, Collins PW: Haemostatic monitoring during postpartum haemorrhage and implications for management. $\mathrm{Br}$ 」 Anaesth 2012, 109:851-863.

6. Mosesson MW: Fibrinogen and fibrin structure and functions. J Thromb Haemost 2005, 3:1894-1904.

7. Karlsson M, Ternstrom L, Hyllner M, Baghaei F, Flinck A, Skrtic S, Jeppsson A: Prophylactic fibrinogen infusion reduces bleeding after coronary artery bypass surgery. A prospective randomised pilot study. Thromb Haemost 2009, 102:137-144.

8. Rahe-Meyer N, Solomon C, Hanke A, Schmidt DS, Knoerzer D, Hochleitner G, Sorensen B, Hagl C, Pichlmaier M: Effects of fibrinogen concentrate as first-line therapy during major aortic replacement surgery: a randomized, placebo-controlled trial. Anesthesiology 2013, 118:40-50.

9. Charbit B, Mandelbrot L, Samain E, Baron G, Haddaoui B, Keita H, Sibony O, Mahieu-Caputo D, Hurtaud-Roux MF, Huisse MG, Denninger MH, de Prost D, PPH Study Group: The decrease of fibrinogen is an early predictor of the severity of postpartum hemorrhage. J Thromb Haemost 2007, 5:266-273.

10. Schochl H, Cotton B, Inaba K, Nienaber U, Fischer H, Voelckel W, Solomon C: FIBTEM provides early prediction of massive transfusion in trauma. Crit Care 2011, 15:R265.

11. Tauber H, Innerhofer P, Breitkopf R, Westermann I, Beer R, El Attal R, Strasak A, Mittermayr M: Prevalence and impact of abnormal ROTEM(R) assays in severe blunt trauma: results of the 'Diagnosis and Treatment of Trauma-Induced Coagulopathy (DIA-TRE-TIC) study'. Br J Anaesth 2011, 107:378-387.

12. Inaba K, Karamanos E, Lustenberger T, Schochl H, Shulman I, Nelson J, Rhee P, Talving P, Lam L, Demetriades D: Impact of fibrinogen levels on outcomes after acute injury in patients requiring a massive transfusion. $J$ Am Coll Surg 2013, 216:290-297.

13. Stinger HK, Spinella PC, Perkins JG, Grathwohl KW, Salinas J, Martini WZ, Hess JR, Dubick MA, Simon CD, Beekley AC, Wolf SE, Wade CE, Holcomb JB: The ratio of fibrinogen to red cells transfused affects survival in casualties receiving massive transfusions at an army combat support hospital. J Trauma 2008, Suppl 2:579-85.

14. Schochl H, Forster L, Woidke R, Solomon C, Voelckel W: Use of rotation thromboelastometry (ROTEM) to achieve successful treatment of polytrauma with fibrinogen concentrate and prothrombin complex concentrate. Anaesthesia 2010, 65:199-203.

15. Schochl H, Nienaber U, Maegele M, Hochleitner G, Primavesi F, Steitz B, Arndt C, Hanke A, Voelckel W, Solomon C: Transfusion in trauma: thromboelastometry-guided coagulation factor concentrate-based therapy versus standard fresh frozen plasma-based therapy. Crit Care 2011, 15:R83.

16. Rourke C, Curry N, Khan S, Taylor R, Raza I, Davenport R, Stanworth S, Brohi K: Fibrinogen levels during trauma hemorrhage, response to replacement therapy, and association with patient outcomes. J Thromb Haemost 2012, 10:1342-1351.

17. Ziegler B, Schimke C, Marchet P, Stogermuller B, Schochl H, Solomon C: Severe pediatric blunt trauma-successful ROTEM-guided hemostatic therapy with fibrinogen concentrate and no administration of fresh frozen plasma or platelets. Clin Appl Thromb Hemost 2013, 19:453-9.

18. Wafaisade A, Lefering R, Maegele M, Brockamp T, Mutschler M, Lendemans S, Banerjee M, Bouillon B, Probst C, Trauma Registry of DGU: Administration of fibrinogen concentrate in exsanguinating trauma patients is associated with improved survival at 6 hours but not at discharge. J Trauma Acute Care Surg 2013, 74:387-395.

19. Spahn DR, Bouillon B, Cerny V, Coats TJ, Duranteau J, FernandezMondejar E, Filipescu D, Hunt BJ, Komadina R, Nardi G, Neugebauer E, Ozier Y, Riddez L, Schultz A, Vincent JL, Rossaint R: Management of bleeding and coagulopathy following major trauma: an updated European guideline. Crit Care 2013, 17:R76.

20. Schöchl $H$, Frietsch T, Pavelka M, Jambor C: Hyperfibrinolysis after major trauma: differential diagnosis of lysis patterns and prognostic value of thrombelastometry. J Trauma 2009, 67:125-131.

21. Schochl H, Solomon C, Traintinger S, Nienaber U, Tacacs-Tolnai A, Windhofer C, Bahrami S, Voelckel W: Thromboelastometric (ROTEM) 
findings in patients suffering from isolated severe traumatic brain injury. J Neurotrauma 2011, 28:2033-2041.

22. Schochl H, Maegele M, Solomon C, Gorlinger K, Voelckel W: Early and individualized goal-directed therapy for trauma-induced coagulopathy. Scand I Trauma Resusc Emerg Med 2012, 20:15

23. Toulon P, Ozier Y, Ankri A, Fleron MH, Leroux G, Samama CM: Point-of-care versus central laboratory coagulation testing during haemorrhagic surgery. A multicenter study. Thromb Haemost 2009, 101:394-401.

24. Huissoud C, Carrabin N, Audibert F, Levrat A, Massignon D, Berland M, Rudigoz RC: Bedside assessment of fibrinogen level in postpartum haemorrhage by thrombelastometry. BJOG 2009, 116:1097-1102

25. Frith D, Goslings JC, Gaarder C, Maegele M, Cohen MJ, Allard S, Johansson PI, Stanworth S, Thiemermann C, Brohi K: Definition and drivers of acute traumatic coagulopathy: clinical and experimental investigations. J Thromb Haemost 2010, 8:1919-1925.

26. Lier H, Bottiger BW, Hinkelbein J, Krep H, Bernhard M: Coagulation management in multiple trauma: a systematic review. Intensive Care Med 2011, 37:572-582.

27. Fenger-Eriksen C, Ingerslev J, Sorensen B: Fibrinogen concentrate-a potential universal hemostatic agent. Expert Opin Biol Ther 2009, 9:1325-1333.

28. Corum $L E$, Hlady V: The effect of upstream platelet-fibrinogen interactions on downstream adhesion and activation. Biomaterials 2012, 33:1255-1260

29. Cohen MJ, Kuttcher M, Redick B, on behalf of the PROMMTT study group: Clinical and mechanistics drivers of acute traumatic coagulopathy. J Trauma

30. Davenport R, Manson J, De'Ath H, Platton S, Coates A, Allard S, Hart D, Pearse R, Pasi KJ, MacCallum P, Stanworth S, Brohi K: Functional definition and characterization of acute traumatic coagulopathy. Crit Care Med 2011, 39:2652-2658.

31. Floccard B, Rugeri L, Faure A, Saint Denis M, Boyle EM, Peguet O, Levrat A Guillaume C, Marcotte G, Vulliez A, Hautin E, David JS, Négrier C, Allaouchiche B: Early coagulopathy in trauma patients: an on-scene and hospital admission study. Injury 2012, 43:26-32.

32. Schlimp CJ, Cadamuro J, Solomon C, Redl H, Schochl H: The effect of fibrinogen concentrate and factor XIII on thromboelastometry in 33\% diluted blood with albumin, gelatine, hydroxyethyl starch or saline in vitro. Blood Transfus 2012, 1-9.

33. Martini WZ, Pusateri AE, Uscilowicz JM, Delgado AV, Holcomb JB: Independent contributions of hypothermia and acidosis to coagulopathy in swine. J Trauma 2005, 58:1002-1009.

34. White NJ, Martin EJ, Brophy DF, Ward KR: Coagulopathy and traumatic shock: characterizing hemostatic function during the critical period prior to fluid resuscitation. Resuscitation 2010, 81:111-116.

35. Cotton BA, Dossett LA, Haut ER, Shafi S, Nunez TC, Au BK, Zaydfudim V, Johnston M, Arbogast P, Young PP: Multicenter validation of a simplified score to predict massive transfusion in trauma. J Trauma 2010, Suppl 1: S33-39.

36. Schochl H, Voelckel W, Maegele M, Solomon C: Trauma-associated hyperfibrinolysis. Hamostaseologie 2012, 32:22-27.

37. Solomon C, Cadamuro J, Ziegler B, Schochl H, Varvenne M, Sorensen B, Hochleitner $G$, Rahe-Meyer N: A comparison of fibrinogen measurement methods with fibrin clot elasticity assessed by thromboelastometry, before and after administration of fibrinogen concentrate in cardiac surgery patients. Transfusion 2011, 51:1695-1706.

38. Hiippala ST: Dextran and hydroxyethyl starch interfere with fibrinogen assays. Blood Coagul Fibrinolysis 1995, 6:743-746.

39. Adam S, Karger R, Kretschmer V: Photo-optical methods can lead to clinically relevant overestimation of fibrinogen concentration in plasma diluted with hydroxyethyl starch. Clin Appl Thromb Hemost 2010, 16:461-471.

40. Adam S, Karger R, Kretschmer V: Influence of different hydroxyethyl starch (HES) formulations on fibrinogen measurement in HES-diluted plasma. Clin Appl Thromb Hemost 2010, 16:454-460.

41. Fries $D$, Innerhofer $P$, Reif $C$, Streif $W$, Klingler $A$, Schobersberger $W$, VelikSalchner C, Friesenecker B: The effect of fibrinogen substitution on reversal of dilutional coagulopathy: an in vitro model. Anesth Analg 2006, 102:347-351.

42. Grottke O, Braunschweig T, Henzler D, Coburn M, Tolba R, Rossaint R: Effects of different fibrinogen concentrations on blood loss and coagulation parameters in a pig model of coagulopathy with blunt liver injury. Crit Care 2010, 14:R62.

43. Ranucci M, Solomon C: Supplementation of fibrinogen in acquired bleeding disorders: experience, evidence, guidelines, and licences. $\mathrm{Br} J$ Anaesth 2012, 109:135-137.

44. Fries D: Fibrinogen concentrate (FGTW) in trauma patients, presumed to bleed (Fl in TIC). 2013 [http://clinicaltrials.gov/show/NCT01475344], Accessed June 21.

45. Singbartl $K$, Innerhofer $P$, Radvan J, Westphalen B, Fries D, Stogbauer R, Van Aken H: Hemostasis and hemodilution: a quantitative mathematical guide for clinical practice. Anesth Analg 2003, 96:929-935.

46. Baker SP, O'Neill B, Haddon W Jr, Long WB: The injury severity score: a method for describing patients with multiple injuries and evaluating emergency care. J Trauma 1974, 14:187-196.

doi:10.1186/cc12816

Cite this article as: Schlimp et al:: Estimation of plasma fibrinogen levels based on hemoglobin, base excess and Injury Severity Score upon emergency room admission. Critical Care 2013 17:R137.

\section{Submit your next manuscript to BioMed Central and take full advantage of:}

- Convenient online submission

- Thorough peer review

- No space constraints or color figure charges

- Immediate publication on acceptance

- Inclusion in PubMed, CAS, Scopus and Google Scholar

- Research which is freely available for redistribution
Ciomed Central 